\title{
COMENTARIO EDITORIAL: Resistencia al oseltamivir de los virus de la influenza estacional A (H1N1) durante la temporada 2008-2009
}

\author{
Resistance of seasonal Influenza A virus to oseltamivir during 2008-2009 period
}

Agustín Ciapponi, Fernando Rubinstein y Sebastián García Martí*

\begin{abstract}
Resumen
En el contexto de la pandemia de gripe A (H1N1) los autores describen la situación mundial de resistencia al oseltamivir (Tamiflu NR) de los virus de la gripe estacional (no pandémica) y las posibilidades de que ésta se desarrolle para el virus de la gripe pandémica en el Hemisferio Sur, las actuales recomendaciones de tratamiento de Argentina y las dificultades para estimar la letalidad de esta enfermedad derivadas de la falta de denominadores confiables del número de casos existentes.
\end{abstract}

\section{Abstract}

In the context of (H1N1) A Influenza pandemia, the authors describe the pattern of resistance to oseltamivir (Tamiflú NR) of the seasonal (non pandemic) influenza virus in the world and the likelihood of its ocurrence in the South Hemisphere; the current therapeutic recommendations in Argentina; and the difficulties to estimate the fatality rate of this disease due to the absence of reliable denominator on existing cases.

Palabras clave: influenza A, oseltamivir, resistencia, pandemia. Key words: A influenza, oseltamivir, resistence, pandemia.

Ciapponi A, Rubinstein F y García Martí S. Resistencia al oseltamivir de los virus de la influenza estacional A (H1N1) durante la temporada 2008-2009.Evid Act Pract Ambul. 12(3). 82-84. Jul-Sep. 2009.

Durante las primeras cuatro semanas de 2009 (28 de diciembre de 2008 a 24 de enero de 2009) el nivel de actividad global de la gripe estacional en el mundo fue aumentando".

En Europa, la mayoría de los países tuvieron una amplia actividad del virus de la gripe A predominantemente del subtipo $\mathrm{H} 3$. Se informó actividad generalizada de influenza $\mathrm{A}$ ( $\mathrm{H} 1$ y H3) en Japón; mientras que en Canadá, Hong Kong y los Estados Unidos, la gripe aumentó, pero la actividad sigue siendo relativamente baja. Por otro lado, y por mencionar un país latinoamericano, hubo casos esporádicos actividad gripal en Brasil (A).

La Organización Mundial de la Salud (OMS) coordina la recopilación global de datos de múltiples laboratorios que participan en Red Mundial de Vigilancia de la Gripe.

Durante este período, un total de 30 países de todas las regiones de la OMS informaron resistencia al oseltamivir en 1291 de 1362 virus $A(H 1 N 1)$ analizados. La prevalencia de la resistencia a oseltamivir fue muy alta en Canadá, Hong Kong, Japón, la República de Corea y los Estados Unidos de América. (Ver tabla 1). Por otro lado, la prevalencia de resistencia fue relativamente baja en China; mientras que en Europa, la circulación de H1N1 fue baja durante este período, mientras que la prevalencia de resistencia fue alta.

Los datos de resistencia al oseltamivir de las cepas de Influenza A (H1N1) emitidos por la OMS el 18 de Marzo de $2009^{1}$ no corresponden al virus emergente actual, llamado A (H1N1) pandémico, sino a las cepas de Influenza estacional circulantes en ese momento en todo el mundo, que ostentan la misma denominación de su hemaglutinina $(\mathrm{H})$ y Neuraminidasa $(\mathrm{N})$.

Estos datos mostraron un alto porcentaje de resistencia del virus de la gripe estacional A (H1N1) al oseltamivir y un veloz crecimiento de la tendencia a nivel global que pasó de $44 \%$ en la mitad de 2008, a 95\% a finales de 2008 y comienzo del 2009. (Ver tabla 1).

En EEUU, durante la pasada campaña de gripe $\mathrm{H} 1 \mathrm{~N} 1$ no porcina, un $90 \%$ de las cepas se hicieron resistentes al oseltamivir, lo cual no es sorprendente desde el punto de vista biológico. El Comité Asesor del Centro para el Control de Enfermedades (sigla en inglés $\mathrm{CDC}$ ) de los Estados Unidos, comprobó, que, a diferencia de otros antivirales, más del 99\% de las cepas de los virus aislados, incluyendo la cepa H1N1, respondieron positivamente al tratamiento con zanamivir.

La Agencia Americana de Médicos de Familia (AAFP) adoptó las guías del CDC para el uso de antivirales durante la epidemia de gripe A (H1N1) de 2008-2009, recomendando el uso del zanamivir como tratamiento de primera línea de la Gripe A (H1N1) o la combinación de oseltamivir y rimantadina como opciones más apropiadas. Se considera que es probable que esta cepa del virus también acabe desarrollando resistencia al zanamivir $^{2}$

El 29 de junio de 2009, se detectó en Dinamarca el primer caso de resistencia al oseltamivir por parte del nuevo virus Influenza $\mathrm{A}(\mathrm{H} 1 \mathrm{~N} 1)$ Pandémico de origen porcino. El paciente fue subsiguientemente tratado con el otro inhibidor de la neuraminidasa viral disponible (zanamivir) recuperándose de su enfermedad. La OMS declaró que este caso aislado no tiene significación epidemiológica en el contexto global de la pandemia, aunque sugiere realizar un estricto monitoreo del comportamiento viral en las próximas semanas / meses.

El pasado 7 de julio, el Dr Keiji Fukuda, Director General Asistente de la OMS, comentó en conferencia de prensa los tres casos que hasta hoy fueron identificados con cepas de Influenza A (H1N1) pandémica resistente a oseltamivir ${ }^{3}$. Los casos identificados en Dinamarca y en Japón habían recibido oseltamivir profiláctico. Fukuda sostuvo que no hay aún evidencia para pensar que una cepa resistente estuviera circulando y que estos casos impresionan como mutaciones espontáneas en estos pacientes. Sin embargo, el caso ocurrido en Hong Kong fue en una paciente adolescente que no había sido tratada con la droga, sugiriendo el contagio directo de otro paciente con una cepa resistente.

Debido a la rápida resistencia al oseltamivir generada por el virus A (H1N1) estacional, no es improbable pensar que cepas del virus responsable de la pandemia actual puedan también desarrollarla, en especial si el uso de la droga no se restringe a los casos indicados y comienza a ser utilizada y prescripta como "preventivo" o vendida sin control.

Una muy interesante editorial aparecida en el último número del New England Journal of Medicine, cuyo sugestivo título es "Forever unprepared" (por siempre no preparados) Sepkowitz discute en un tono ácido, la impredecibilidad del comportamiento de los patógenos, sosteniendo que la resistencia demostrada por el virus al oseltamivir no se debe al sobreuso de la droga sino a una simple mutación $n^{4}$. Aunque el debate sobre el tema siempre está abierto, tambien es verdad que el uso no controlado del oseltamivir puede provocar la selección de una cepa resistente, por lo que la rápida aparición de resistencia hace cuestionable la

\footnotetext{
* Servicio de Medicina Familiar y Comunitaria del Hospital Italiano de Buenos Aires. agustin.ciapponi@ hospitalitaliano.org.ar fernando.rubinstein@hospitalitaliano.org.ar,
} sebastian.garcia@ hospitalitaliano.org.ar 
generalización del uso de estos antivirales.

Su prescripción quizás debería limitarse, a los casos de gravedad clínica, los pacientes con inmunosupresión o con enfermedades de base y luego de un análisis juicioso de los llamados casos sospechosos.

Hasta el momento de este informe, no existen datos de Argentina sobre caracterización genómica de cepas de dicho virus que permitan establecer la eventual resistencia al oseltamivir. Para el caso de Argentina, la resistencia en el primer período a las cepas estacionales del de Influenza A (H1N1) fue de $50 \%$, pero carecemos de datos recientes en la actual situación de la epidemia. Es importante que se realice el monitoreo y se logre determinar el nivel de resistencia actual del virus Influenza A (H1N1) pandémico, ya que el oseltamivir integra la primera línea terapéutica. En el país se acordó recientemente la unificación de su tratamiento, que incluirá $\mathrm{a}^{5}$ :

- todo paciente con infección respiratoria aguda grave que requiera hospitalización, independientemente del tiempo de evolución de los síntomas;

- a las personas calificadas como caso sospechoso y pertenezca a alguno de los grupos de riesgo para la vacunación contra gripe estacional, dentro de las 48 horas de iniciados los síntomas;

- toda persona mayor de 15 años, calificada como caso sospechoso, también dentro de las 48 horas de iniciados los síntomas

Se considera caso sospechoso a toda persona que presente enfermedad respiratoria aguda febril (mayor a $38^{\circ} \mathrm{C}$ ) en un espectro que va de enfermedad tipo influenza (tos o dolor de garganta y ausencia de otras causas) a neumonía ${ }^{6}$.

La resistencia al oseltamivir del virus de la influenza A (H1N1) estacional comunicada por la OMS es llamativamente alta e indudablemente preocupante y determina la necesidad de mantener una estricta vigilancia en las próximas semanas, ya que si estas tendencias globales se repitiesen para el virus Influenza A (H1N1) de origen porcino, la recomendación actual del tratamiento en nuestro país debería ser revisada y considerarse antivirales alternativos como el zanamivir. Aunque aún es prematuro hablar sobre resistencia al oseltamivir por parte del virus actual, es un dato más a tener en cuenta y que habrá que observar en su evolución. Existe una gran incertidumbre con respecto a la severidad de esta enfermedad, ya que no se conoce con certeza el denominador de casos totales a partir del cual surge el número de casos severos. Si los casos leves o moderados no están siendo confirmados y, por ende, reportados, los desenlaces más graves se estimarán en una población menor de casos reportados, lo que hace que la letalidad o las tasas de hospitalización que se calculen, se vean sobredimensionadas ${ }^{7}$. En estos casos las tasas de mortalidad por millón de habitantes permitirían una comparación más confiable con períodos previos y entre países.

Se muestra la figura 1, que incluye un gráfico que relaciona las muertes reportadas con la población de cada país. Los datos de mortalidad fueron obtenidos de los informes de situación de la $\mathrm{OMS}^{8}$ para relacionarla con la población de los países ${ }^{9}$ por cada millón de habitantes. Se observa el incremento de muertes en Argentina y la estabilidad de los datos en México al haber finalizado el proceso en dicho país al momento de las fechas analizadas.

Uno puede asumir que estimar el número de muertes por A (H1N1) utilizando como denominador la cantidad de habitantes esta mucho menos sesgado que utilizar como denominador la cantidad de casos, que es mucho más variable en su forma de registro . $^{\text {. }}$

Si lo relacionamos con la población total del país, si bien no se obtiene una tasa de letalidad, brinda una idea global de la "carga fatal" de esta enfermedad, y puede hasta considerar que la propagación no sea uniforme en los distintos países. Es de notar que países como Estados Unidos y México pertenecen al hemisferio norte, por lo que el comportamiento de la epidemia es diferente a paises como Argentina, Chile y Uruguay que actualmente están en la mitad de la estación de gripe ${ }^{10}$.

Si bien es importante no crear pánico en la población, sería necio desatender el potencial impacto y severidad de la epidemia que esta afectando población relativamente joven y sana, que tiene una menor inmunidad contra esta nueva cepa, causando una alta tasa de hospitalizaciones y algunas muertes en población tradicionalmente a salvo de la influenza.

Expertos en el mundo coinciden en que es probable que el hemisferio sur se vea considerablemente afectado y que las tasas de ataque del virus $\mathrm{A}(\mathrm{H} 1 \mathrm{~N} 1)$ responsable de la pandemia excedan las usuales tasas de ataque de la gripe estacional antes de que la vacuna este disponible.

Mientras tanto, será vital mantener todas las medidas generales de protección necesarias para limitar la propagación de la epidemia, entre las cuales se deben destacar la responsabilidad en el manejo de la información por parte de las autoridades sanitarias así como la responsabilidad y el sentido común por parte de toda la población.

Figura 1: comparación de la carga fatal de influenza pandémica (H1N1) entre el 26/06/09 y el 13/07/09. El gráfico muestra el número de casos mortales cada millón de habitantes en cada uno de los puntos temporales de medición.

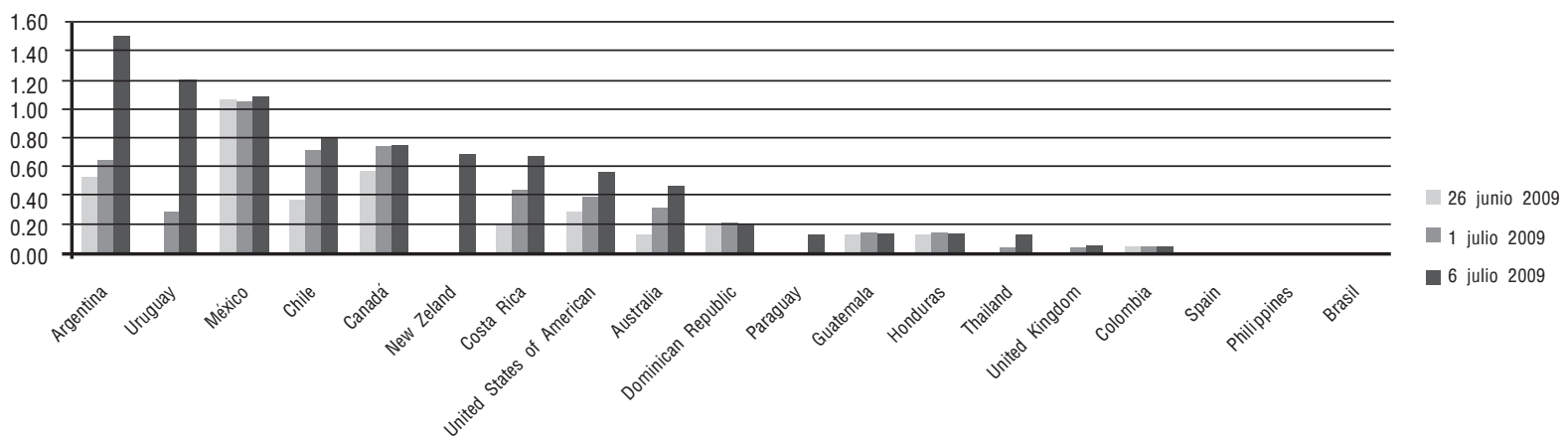

Elaborada por los autores de este artículo. Fuentes: Global Alert and Response (GAR). Situation updates - Pandemic (H1N1) 2009. Disponible en URL: http://www.who.int/csr/disease/swineflu/updates/en/index.html (último acceso 13/09/09). List of countries by population. From Wikipedia, the free encyclopedia. Disponible en URL: http://en.wikipedia.org/wiki/List_of_countries_by_population (último acceso 13/09/09).

$\S$ Igualmente debe considerarse que el registro de la cantidad de muertes atribuida a la gripe A (H1N1) porcina también puede variar de país a país. 
Tabla 1: resistencia del virus de de la gripe A (H1N1) al oseltamivir (2008-2009).

\begin{tabular}{|c|c|c|c|c|c|}
\hline \multirow[b]{2}{*}{ Región OMS } & \multirow[b]{2}{*}{ País, área o territorio } & \multicolumn{2}{|c|}{ Número de aislamientos de H1N1 } & \multicolumn{2}{|c|}{ Porcentaje de virus resistentes al oseltamivir } \\
\hline & & $1 / 4$ al $30 / 9$ de 2008 & $31 / 9 / 2008$ al $31 / 1 / 2009$ & $1 / 4$ al $30 / 9$ de 2008 & $31 / 9 / 2008$ al $31 / 1 / 2009$ \\
\hline \multirow[t]{5}{*}{ Africa } & Ghana & 22 & 1 & $59 \%$ & \\
\hline & Madagascar & 9 & 7 & $0 \%$ & \\
\hline & Senegal & 10 & - & $100 \%$ & \\
\hline & Sudáfrica & 225 & - & $100 \%$ & \\
\hline & Africa Total & 292 & 8 & $89 \%$ & \\
\hline \multirow{11}{*}{ Americas } & Argentina & 36 & 1 & $50 \%$ & \\
\hline & Brasil & 18 & & $22 \%$ & \\
\hline & Canadá & 2 & 52 & $50 \%$ & $100 \%$ \\
\hline & Chile & 90 & & $13 \%$ & \\
\hline & Costa Rica & 19 & 1 & $74 \%$ & \\
\hline & El Salvador & 32 & & $66 \%$ & \\
\hline & México & 3 & 5 & $33 \%$ & \\
\hline & Puerto Rico & - & 1 & - & \\
\hline & Estados Unidos & 10 & 241 & $30 \%$ & $98 \%$ \\
\hline & Uruguay & 17 & & $82 \%$ & \\
\hline & Américas Total & 275 & 301 & $36 \%$ & $\mathbf{9 8} \%$ \\
\hline \multicolumn{2}{|c|}{ Mediterráneo Oriental Total } & 2 & 10 & $50 \%$ & $100 \%$ \\
\hline \multirow{15}{*}{ Europa } & Francia & - & - & - & $100 \%$ \\
\hline & Alemania & - & 10 & - & $99 \%$ \\
\hline & Grecia & - & 12 & - & \\
\hline & Irlanda & - & 67 & - & $90 \%$ \\
\hline & Israel & - & 1 & - & \\
\hline & Italia & - & 10 & - & $100 \%$ \\
\hline & Holanda & 2 & 1 & $50 \%$ & \\
\hline & Noruega & 8 & 16 & $75 \%$ & \\
\hline & Portugal & - & 4 & - & \\
\hline & Federación Rusa & 20 & 9 & $45 \%$ & \\
\hline & Eslovaquia & - & 3 & - & \\
\hline & España & - & 6 & - & \\
\hline & Suecia & - & 1 & - & $92 \%$ \\
\hline & Reino Unido & 1 & 5 & $100 \%$ & $98 \%$ \\
\hline & Europa Total & 31 & 209 & $55 \%$ & $\mathbf{9 8} \%$ \\
\hline \multicolumn{2}{|l|}{ Asia Sudoriental Total } & 13 & 12 & $0 \%$ & $92 \%$ \\
\hline \multirow{8}{*}{ Pacífico Occidental } & Australia & 76 & & $93 \%$ & \\
\hline & China & 583 & 44 & $17 \%$ & $14 \%$ \\
\hline & China, Hong Kong SAR & & 80 & & $90 \%$ \\
\hline & Filipinas & 11 & - & $91 \%$ & - \\
\hline & Japón & 7 & 422 & $14 \%$ & $100 \%$ \\
\hline & República de Corea & - & 269 & - & $100 \%$ \\
\hline & Singapur & - & 7 & - & \\
\hline & Vietnam & 31 & & $68 \%$ & \\
\hline \multirow{2}{*}{\multicolumn{2}{|c|}{ Pacífico Oriental Total }} & 731 & 822 & $29 \%$ & $94 \%$ \\
\hline & & 1344 & 1362 & $44 \%$ & $95 \%$ \\
\hline
\end{tabular}

Adaptada de la tabla sumaria'. La resistencia al oseltamivir se basa en los resultados fenotípicos y / o análisis genotípicos. Se presentan la totalidad de los países del último período y los países con más de diez casos o que también hayan sido reportados en el último período. † El porcentaje (\%) no se muestra si el número de de virus analizados fue menor a diez.

Recibido el 08/07/09 y aceptado el 13/07/09.

Referencia

1. Influenza A (H1N1) virus resistance to oseltamivir - 2008/2009 influenza season. WHO 18 March 2009. Disponible en: http:/hww.who.int/csr/disease/influenza/H1N1webupdate20090318\%20ed_ns.pdf 2. http://www.aafp.org/online/en/home/publications/news/news-now/clinical-care-research/20090122oseltamivir-recs.html

3. http://www.natap.org/2009/newsUpdates/070909_04.htm

4.Sepkowitz K, Forever Unprepared - The Predictable Unpredictability of Pathogens NEJM Volume 361:120-121,July 9,2009. Disponible en http://content.nejm.org/cgi/content/short/361/2/120?query=TOC

5. Ministros de salud de todo el país unificaron criterios para el tratamiento de las personas afectadas por la influenza A H1N1 6/7/2009.

Disponible en: http://www.msal.gov.ar/htm/Site/noticias_plantilla.asp?ld=1475

6. Definición de casos y recomendaciones. Disponible en: http://municipios.msal.gov.ar/h1n1/5_equipos/plan_c/definicion-casos-recomen-inf.pdf

7. Lipsitch,M. Managing and Reducing Uncertainty in an Emerging Influenza Pandemic. NEJM Volume 361:112-115, July 9,2009.

8. Global Alert and Response (GAR). Situation updates - Pandemic (H1N1) 2009. Disponible en URL: http://www.who.int/csr/disease/swineflu/updates/en/index.html (último acceso 13/09/09).

9. List of countries by population. From Wikipedia, the free encyclopedia. Disponible en URL: http://en.wikipedia.org/wiki/List_of_countries_by_population (último acceso 13/09/09).

10. Viboud C y col. (2006) Influenza in Tropical Regions. PLoS Med 3(4): e89. doi:10.1371/journal.pmed.0030089.

Disponible en URL: http://www.plosmedicine.org/article/info\%3Adoi\%2F10.1371\%2Fjournal.pmed.0030089 (último acceso 14/07/09). 